\title{
ASSESSMENT OF KNOWLEDGE, ATTITUDE, AND PRACTICE REGARDING HYPOTHYROIDISM AMONG INFERTILE WOMEN WITH HYPOTHYROIDISM
}

\author{
VIMALA DEVA PRASANNA $\mathrm{G}^{1}$, SHARUMATHI SM ${ }^{1}$, SHANMUGA SUNDARAM R ${ }^{2 *}$ \\ ${ }^{1}$ Department of Pharmacy Practice, J. K. K. Nattraja College of Pharmacy, Namakkal, Tamil Nadu, India. ${ }^{2}$ Department of Pharmacology, \\ J. K. K. Nattraja College of Pharmacy, Namakkal, Tamil Nadu, India. Email: malshan34@gmail.com
}

Received: 18 May 2020, Revised and Accepted: 30 June 2020

\section{ABSTRACT}

Objective: The study was designed to assess the knowledge, attitude, and practice (KAP) of hypothyroidism among infertile women with hypothyroidism.

Methods: A cross-sectional analysis was performed in an outpatient environment of infertility centers. We used a validated questionnaire to assess hypothyroidism KAP. Using frequency counts (n) and percentages (\%), discrete data were summarized. The Chi-square/Fisher test was used between groups to compare.

Results: The mean age of participants was found to be $32 \pm 5.77$ years. It was found that $72 \%$ of the subjects had poor knowledge, $44 \%$ were extremely concerned, and $81 \%$ were practicing with a moderate level of precaution. Among the consequences of hypothyroidism, $68 \%$ of the study subjects most properly-recognized menstrual disturbance, followed by $66 \%, 51 \%$, and $48 \%$ of study subject properly-recognized weight gain, fatigue, and muscle aches/pain as a clinical manifestation of hypothyroidism. Most patients (98\%) adhered to their medications. Nearly half of the study patients (45\%) did not avoid cabbage, cauliflower, or soya.

Conclusion: Our study highlighted the significance of investing appropriate time to provide patients with a comprehensive education to bridge the gaps in patient care. The findings also indicated that it be better for the understanding of the patients if health-care providers could provide patients with data sheets explaining the disease or having some pictorial/pamphlets about the disease's reality and myths.

Keywords: Hypothyroidism, Knowledge, Attitude, Practice, Patient education.

(c) 2020 The Authors. Published by Innovare Academic Sciences Pvt Ltd. This is an open access article under the CC BY license (http://creativecommons. org/licenses/by/4. 0/) DOI: http://dx.doi.org/10.22159/ajpcr.2020.v13i9.38401

\section{INTRODUCTION}

Hypothyroidism is still the most commonly diagnosed endocrine disorder in India, with a prevalence of 3.9-10.95\% [1]. It occurs mainly in women of 21-40 years age [2]. Thyroid disease varies by geographic location, environmental factors, major radio nuclear activities, factors affecting the incidence and duration of iodine deficiency, the excess dietary iodine, and the population studied [3]. Hypothyroidism is among the severest disorders characterized by a broad medical continuum ranging from open myxedema, end-organ symptoms, and multisystem failure to an asymptomatic or subclinical disorder with normal thyroxine and triiodothyronine levels and slightly elevated serum thyrotropin levels [4-6]. Adding more a low-functioning thyroid gland is prevalent in females, resulting in a significant percentage of infertility, repeated miscarriages, preterm delivery, placenta previa, irregular menstrual cycles, and unexplained weight loss or gain $[7,8]$. The majority of infertile women have hypothyroidism and hyperprolactinemia that may correlate with infertility [9]. Research shows that hypothyroidism may contribute to the morbidity of osteoporosis, hyperlipidemia, hypercholesterolemia, cardiac disease, asthma, and neuropsychiatric disorder [10]. The general knowledge of hypothyroidism in India has been recognized as weak and in a significant proportion of patients is associated with inadequate knowledge, misconceptions, and practices [11]. The lacunae found in hypothyroid patients regarding information and procedures resulted in a number of misunderstandings, inadequate adherence, and suboptimal management $[11,12]$. One of several important factors that contribute to this observed gap is the lack of qualified doctors to treat hypothyroidism. Another contributing factor is the inadequate amount of time doctors spend on patient education. Many kinds of research were conducted to assess the patient's knowledge regarding hypothyroidism among the general hypothyroid population. This research aims to analyze the knowledge gaps, faulty practices, and myths of hypothyroidism, especially in a subpopulation called infertile women with hypothyroidism because this subpopulation should be more concerned about hypothyroidism for the success of infertility treatment.

\section{METHODS}

The research was performed over a span of 6 months in a private hospital. It obtained ethical clearance from the Institutional Ethical Committee for the study. Infertile female patients of fertility age with hypothyroidism were chosen for analysis. Patients who underwent thyroid surgery and radio ablation therapy were excluded from the study.

- A separate questionnaire was prepared to record patient details such as name, age, sex, educational status, family history, medical history, and prescribed drugs. It also included questions for assessing their hypothyroidism knowledge, attitude, and practice (KAP)

- After obtaining an informed consent form from the patient, the demographic data such as age, gender, educational status, diagnosis, and prescriptions were collected along with answers for KAP regarding hypothyroidism

- The questionnaires from 120 patients for their KAP of hypothyroidism were collected, evaluated, and scored

- The rating evaluations of the three KAP domains were performed as follows:

1. For the sake of knowledge, each correct answer ("Yes" for positive statements and "No" for negative statements) was given 1 point and an incorrect response ("No" for positive statements and "Yes" for negative statements) was given 0 points including "Don't know." Based on the overall score, the knowledge level 
was graded as "low" (nearly 12 points), normal (13-15 points), or "high" (nearly 16 points)

2. For attitude, the level of concern was classified as "extremely concerned" (if the agreement was marked for all five statements [points 4 or 5 on the Likert scale]), "quite concerned" (if the agreement was shown for 3-4 statements), "little concern" (if the agreement was marked for 1-2 statements), and "not concerned" (no agreement)

Table 1: Demographic data of participants $(n=120)$

\begin{tabular}{ll}
\hline Variables/characteristics & Frequency, n (\%) \\
\hline Age group & \\
$20-25$ & $18(15)$ \\
$25-30$ & $22(18)$ \\
$30-35$ & $34(28)$ \\
$35-40$ & $34(28)$ \\
$40-45$ & $12(10)$ \\
Education level & \\
School & $46(38)$ \\
Diploma & $8(6)$ \\
Undergraduate & $36(30)$ \\
Postgraduate & $30(25)$ \\
\hline
\end{tabular}

n: Total number of patients available with the data
3. For practice, each of the patient's precautionary statements (total score ranged between 0 and 8 points) 1 point was given. For a score of 7 points, a "high level" of precaution was considered, a moderate level "was given when the score was between 4 and 6 points and a poor level" with scores $<3$.

- Discrete data are summarized using the frequency counts (n) and (percentage). All statistical analysis was carried out using a two-sided experiment with a meaning level of 0.05 . The Chi-square/Fisher test was used for comparison between groups.

\section{RESULTS}

It was observed that the mean age of respondents was $32 \pm 5.77$ years. From table 1 it was observed that most patients were not graduates $(38 \%)$ followed by undergraduates $(30 \%)$ and postgraduates $(25 \%)$.

\section{Knowledge about hypothyroidism}

Table 2 summarizes the responses given to all individual questions of the knowledge domain. A good number of patients (43\%) understood the structure of the thyroid gland correctly. Among the consequences of hypothyroidism, $68 \%$ of the study subject most properly-recognized menstrual disturbance, $66 \%$ weight gain, $51 \%$ fatigue, and $48 \%$ muscle ache as a clinical symptom of hypothyroidism. Only $16 \%$ correctly identified cold intolerance and $31 \%$ constipation as manifestations of

Table 2: Responses to knowledge-based questions regarding hypothyroidism

\begin{tabular}{|c|c|c|c|}
\hline \multirow[t]{2}{*}{ Questions } & \multicolumn{3}{|c|}{ Patient response $(n=120)$} \\
\hline & Yes, n (\%) & No, $n(\%)$ & Do not know, n (\%) \\
\hline Thyroid gland is a butterfly-shaped gland, located in the neck & $52(43)$ & $2(01)$ & $66(55)$ \\
\hline Hypothyroidism is not related to increased TSH levels & $26(21)$ & $24(20)$ & $70(58)$ \\
\hline Hypothyroidism may cause cold intolerance & $20(16)$ & $12(10)$ & $88(73)$ \\
\hline Hypothyroidism may cause dry skin & $32(26)$ & $10(08)$ & $78(65)$ \\
\hline Hypothyroidism may cause fatigue & $62(51)$ & $6(05)$ & $52(43)$ \\
\hline Hypothyroidism may cause muscle aches/pain & $58(48)$ & $8(06)$ & $54(45)$ \\
\hline Hypothyroidism may cause constipation & $38(31)$ & $14(11)$ & $68(56)$ \\
\hline Hypothyroidism may cause weight gain & $80(66)$ & $4(3)$ & $36(30)$ \\
\hline Hypothyroidism may cause abnormal menstruation & $82(68)$ & $4(3)$ & $34(28)$ \\
\hline Iodine deficiency in diet may lead to hypothyroidism & $36(30)$ & $4(03)$ & $80(66)$ \\
\hline Patients with hypothyroidism may be at an increased risk of having depression & $38(31)$ & $8(06)$ & $74(61)$ \\
\hline Patients with hypothyroidism might have more risk of having increased cholesterol levels & $44(36)$ & $12(10)$ & $64(53)$ \\
\hline Thyroid disorders run in families & $66(55)$ & $8(06)$ & $46(38)$ \\
\hline Patients with swelling or abnormality in the neck may be suffering from hypothyroidism & $56(46)$ & $6(05)$ & $48(40)$ \\
\hline Hypothyroidism does not occur in pregnancy & $20(16)$ & $26(21)$ & $74(61)$ \\
\hline Hypothyroidism is diagnosed by measuring TSH levels in blood & $52(23)$ & $4(03)$ & $64(53)$ \\
\hline Hypothyroidism is treatable & $40(33)$ & $20(16)$ & $60(50)$ \\
\hline $\begin{array}{l}\text { Alternative forms of medicine, such as Ayurveda and Homeopathy, may be useful to treat } \\
\text { hypothyroidism }\end{array}$ & $20(16)$ & $12(10)$ & $88(73)$ \\
\hline
\end{tabular}

n: Total number of patients available with the data. TSH: Thyroid-stimulating hormone

Table 3: Evaluation of association of different levels of knowledge with age group and educational qualification

\begin{tabular}{|c|c|c|c|c|}
\hline \multirow{2}{*}{$\begin{array}{l}\text { Parameter } \\
\text { Age in years }\end{array}$} & \multicolumn{3}{|c|}{ Different levels of the knowledge domain $(n=120) n(\%)$} & \multirow[t]{2}{*}{ p-value } \\
\hline & Low level ( $\leq 12$ points) & Moderate level (13-15 points) & High level ( $\geq 16$ points) & \\
\hline $20-25$ & $18(15)$ & $00(00)$ & $00(00)$ & $<0.0001$ \\
\hline $25-30$ & $14(11)$ & $8(6)$ & $00(00)$ & \\
\hline $30-35$ & $28(23)$ & $12(10)$ & $6(5)$ & \\
\hline $35-40$ & $16(13)$ & $00(00)$ & $6(5)$ & \\
\hline $40-45$ & $12(10)$ & $00(00)$ & $00(00)$ & \\
\hline Educational qualification & Low level & Moderate level & High level & p-value \\
\hline Others & $40(33)$ & $4(3)$ & $2(1)$ & 0.099 \\
\hline Diploma & $4(03)$ & $2(1)$ & $2(1)$ & \\
\hline Undergraduate & $22(18)$ & $8(6)$ & $6(5)$ & \\
\hline Postgraduate & $22(18)$ & $6(5)$ & $2(1)$ & \\
\hline
\end{tabular}

Chi-square test was used at a $5 \%$ level of significance to evaluate the association of different levels of knowledge with age group and educational qualification. n: Total number of patients available with the data 
Table 4: Responses to attitude-based questions

\begin{tabular}{|c|c|c|c|c|c|}
\hline Questions & Strongly agree & Agree & Neutral & Disagree & Strongly disagree \\
\hline $\begin{array}{l}\text { Women are at a greater risk of developing hypothyroidism and should } \\
\text { be tested at regular intervals for hypothyroidism }\end{array}$ & $20(16)$ & $60(50)$ & $40(33)$ & $00(00)$ & $00(00)$ \\
\hline $\begin{array}{l}\text { People above the age of } 35 \text { years should be tested frequently for } \\
\text { hypothyroidism }\end{array}$ & $18(15)$ & $46(38)$ & $56(46)$ & $00(00)$ & $00(00)$ \\
\hline Pregnant women should be tested for hypothyroidism & $30(25)$ & $48(40)$ & $42(35)$ & $00(00)$ & $00(00)$ \\
\hline $\begin{array}{l}\text { People with relatives/family members diagnosed with hypothyroidism } \\
\text { should be tested for hypothyroidism }\end{array}$ & $18(15)$ & $52(43)$ & $50(41)$ & $00(00)$ & $00(00)$ \\
\hline
\end{tabular}

n: 120 ; n: Total number of patients available with the data, $\mathrm{n}(\%)$

Table 5: Evaluation of association of different levels of attitude with age groups and educational qualification

\begin{tabular}{|c|c|c|c|c|c|}
\hline \multirow{2}{*}{$\begin{array}{l}\text { Parameter } \\
\text { Age in years }\end{array}$} & \multicolumn{4}{|c|}{ Different levels of attitude domain $(n=120) n(\%)$} & \multirow[t]{2}{*}{ P-value } \\
\hline & $\begin{array}{l}\text { Extremely concerned } \\
\text { ( } 5 \text { points) }\end{array}$ & $\begin{array}{l}\text { Quite concerned } \\
\text { (3-4 points) }\end{array}$ & $\begin{array}{l}\text { Little concerned } \\
\text { (1-2 points) }\end{array}$ & $\begin{array}{l}\text { Not concerned } \\
(0 \text { points })\end{array}$ & \\
\hline $20-25$ & $2(01)$ & $10(08)$ & $00(00)$ & $6(05)$ & \multirow[t]{4}{*}{0.0011} \\
\hline $25-30$ & $6(05)$ & $8(6)$ & $00(00)$ & $8(6)$ & \\
\hline $30-35$ & $10(08)$ & $8(6)$ & $6(05)$ & $10(8)$ & \\
\hline $35-40$ & $20(16)$ & $6(5)$ & $00(00)$ & $8(6)$ & \\
\hline Educational qualification & Extremely concerned & Quite concerned & Little concerned & Not concerned & p-value \\
\hline Diploma & $6(5)$ & $00(00)$ & $00(00)$ & $2(01)$ & \multirow[t]{4}{*}{$<0.0001$} \\
\hline Undergraduate & $24(20)$ & $8(6)$ & $00(00)$ & $4(3)$ & \\
\hline Postgraduate & $6(5)$ & $16(13)$ & $2(01)$ & $6(5)$ & \\
\hline Others & $8(6)$ & $12(10)$ & $4(3)$ & $22(18)$ & \\
\hline
\end{tabular}

Chi-square test was used at a $5 \%$ level of significance for the evaluation of the association of different levels of attitude with age groups and educational qualification $\mathrm{n}$ : Total number of patients available with the data

hypothyroidism. Swelling in the neck associated with hypothyroidism was correctly identified by $46 \%$ of patients. Approximately $77 \%$ did not know about the increased risk of hypothyroidism at the time of pregnancy and $44 \%$ of patients were not aware of the possibility that thyroid disorders could become inherited. A large number of patients had inaccurate knowledge of hypercholesterolemia (63.6\%) and hypothyroid-causing drugs (50\%). Most patients (56\%) were not aware that hypothyroidism could be diagnosed by testing thyroid-stimulating hormone (TSH), but $21 \%$ and $50 \%$ of patients had no knowledge about the increased levels of TSH and low thyroid hormone levels in hypothyroidism, respectively. In addition, 70\% of patients had incorrect knowledge that hypothyroidism may result from iodine deficiency. Just $16 \%$ were sure that alternative therapies were not effective in the management of hypothyroidism. Although $50-70 \%$ of participants had a clear awareness of tiredness, obesity, and muscle aches as the related hypothyroidism symptoms, the rest of the participants had no knowledge of any other symptoms associated with hypothyroidism. Over $50 \%$ of the participants were unaware of the genetic predisposition associated with hypothyroidism, which may be the reason for almost $41 \%$ of patients not being aware of having their family members tested for the illness. It is clear from Table 3 that knowledge has no dependency on either age or the educational qualification with statistical evidence.

\section{Attitude}

The responses to the attitude based questions are summarized in Table 4. Most subjects (44\%) were extremely concerned about hypothyroidism. Highest agreement (66\%) was found for the statement, "Women are at a greater risk of developing hypothyroidism and should be tested at regular intervals for hypothyroidism." However, $46 \%$ did not agree that people above the age of 35 years should be tested frequently for hypothyroidism. Overall scores from Table 5 showed that there is no dependency on the attitude with respect to either age or the educational qualification statistically.

\section{Practice}

The practices for hypothyroidism by the subjects are evaluated with the questions, as mentioned in Table 6. Most patients (98\%) adhered to their
Table 6: Response to practice questions

\begin{tabular}{lll}
\hline Questions & Yes n (\%) & No n (\%) \\
\hline $\begin{array}{l}\text { Do you take your medication for } \\
\text { hypothyroidism daily? }\end{array}$ & $118(98)$ & $02(01)$ \\
$\begin{array}{l}\text { Do you miss any doses of your medication } \\
\text { for hypothyroidism? }\end{array}$ & $82(68)$ & $38(31)$ \\
$\begin{array}{l}\text { Do you take your medication } 3060 \text { min } \\
\text { before breakfast on empty stomach? }\end{array}$ & $112(93)$ & $08(06)$ \\
$\begin{array}{l}\text { Do you take your thyroid medicine with any } \\
\text { other medicines? }\end{array}$ & $72(60)$ & $48(40)$ \\
$\begin{array}{l}\text { As advised by your physician, do you get } \\
\text { your TSH level tested regularly? }\end{array}$ & $70(58)$ & $50(41)$ \\
$\begin{array}{l}\text { Do you look for information on } \\
\text { hypothyroidism on the internet/ } \\
\text { smartphone? }\end{array}$ & $14(11)$ & $106(88)$ \\
$\begin{array}{l}\text { Did you ask your doctor for more } \\
\text { information/counseling on how to manage }\end{array}$ & $20(16)$ & $100(83)$ \\
$\begin{array}{l}\text { hypothyroidism? } \\
\text { Do you avoid eating cabbage, cauliflower, } \\
\text { and soya? }\end{array}$ & $66(55)$ & $54(45)$ \\
\hline $\begin{array}{l}\text { n: } 120 ; \text { n: Total number of patients available with the data. TSH: Thyroid- } \\
\text { stimulating hormone }\end{array}$ &
\end{tabular}

medications. However, $68 \%$ responded saying that they occasionally skip medications. About $58 \%$ of patients regularly tested TSH levels. About $60 \%$ said they had taken other medicines with hypothyroid medicines. A considerable number of patients (88\%) did neither look for information from online sources, nor did they (83\%) seek additional information from their doctors. Nearly half of the study patients (45\%) did not avoid cabbage, cauliflower, or soya. According to Table 7, there is no statistical evidence for the association of knowledge with either age or educational qualification.

\section{DISCUSSION}

In nearly three-fourth $(72 \%)$ of a treatment-experienced hypothyroid population, this KAP study identified a lowlevel of understanding. Similar 
Table 7: Evaluation of association of different levels of practice with age groups and educational qualification

\begin{tabular}{|c|c|c|c|c|}
\hline \multirow{2}{*}{$\begin{array}{l}\text { Parameter } \\
\text { Age in years }\end{array}$} & \multicolumn{3}{|c|}{ Different levels of practice domain $(n=120) n(\%)$} & \multirow[t]{2}{*}{ p-value } \\
\hline & $\begin{array}{l}\text { High level of precaution } \\
\text { ( } \geq 7 \text { points) }\end{array}$ & $\begin{array}{l}\text { Moderate level of precaution } \\
\text { (3-6 points) }\end{array}$ & $\begin{array}{l}\text { Poor level of precaution } \\
\text { ( }<3 \text { points) }\end{array}$ & \\
\hline $20-25$ & $2(1)$ & $16(13)$ & $00(00)$ & 0.51 \\
\hline $25-30$ & $2(1)$ & $18(15)$ & $2(1)$ & \\
\hline $30-35$ & $6(5)$ & $24(20)$ & $4(8)$ & \\
\hline $35-40$ & $4(3)$ & $28(23)$ & $2(1)$ & \\
\hline $40-45$ & $00(00)$ & $12(10)$ & $00(00)$ & \\
\hline Educational qualification & High level of precaution & Moderate level of precaution & Poor level of precaution & p-value \\
\hline Diploma & $00(00)$ & $8(06)$ & $00(00)$ & 0.169 \\
\hline Undergraduate & $6(5)$ & $26(21)$ & $4(03)$ & \\
\hline Postgraduate & $6(5)$ & $22(18)$ & $2(1)$ & \\
\hline Others & $2(1)$ & $42(35)$ & $2(1)$ & \\
\hline
\end{tabular}

Chi-square test was used at a $5 \%$ level of significance for the evaluation of the association of different levels of practice with age groups and educational qualification.

$\mathrm{n}$ : Total number of patients available with the data

results were found by Sethi et al., Kumar et al., and Singh et al. [13-15] Over half of the population (55\%) consisted of undergraduates or postgraduates, similar to an analysis by Kumar et al. [13]. Lack of knowledge about the disease in educated individuals is a disturbing aspect of the management of hypothyroidism. About $50 \%$ of respondents had knowledge about the meaning of hypothyroidism; a study by Rai et al. also shows similar results [12]. Symptoms of hypothyroidism are non-specific and likely to overlap with other conditions of the disease. Fatigue is the most common symptom and could be the greatest misleading one too, but in our study, half of the participants identified fatigue as a symptom of hypothyroidism. Similarly, in a study conducted by Sethi et al., a good number of the participants identified fatigue as a clinical symptom of hypothyroidism [14]. Knowledge of disease symptoms is essential for patients to identify treatment effects, disease progression, and to tell a doctor about their clinical experiences during follow-up visits. About $55 \%$ of the study subjects believe hypothyroidism may run through families, but this is in contrast to a study conducted by Kumar et al. where only $12 \%$ believe the genetic cause of hypothyroidism [10]. Likewise, only $21 \%$ of patients were aware of pregnancy hypothyroidism, possibly because they were not conscious that pregnancy hypothyroidism would occur; this is in accordance with a study by Kumar et al. [13]. Complications linked to untreated pregnancy hypothyroidism are diverse and intense, with a higher risk of maternal morbidity, perinatal disease, and death. In this present study, $98 \%$ of the patients are adherent to thyroxine therapy. This result is similar to a study conducted by Sethi et al. [14]. Half of the population believes cabbage, cauliflower, and soya should be avoided. It is been found that $44 \%$ of the study subjects were extremely concerned about hypothyroidism, which was neither influenced by the age nor the educational qualification. It was observed that nearly $80 \%$ of the study subjects found to be practicing with moderate levels of precaution, irrespective of their age, and educational qualification, which was similar to a study done by Sethi et al. [14].

Overall, this study shows that although patients were more aware of symptoms, they were less aware of the risks associated with hypothyroidism, the value of laboratory testing, and dietary precautions. Medication compliance and regular thyroid function testing can only be influenced if patients are aware of the effects of their conditions of disease. Therefore, this aspect can be emphasized in programs for patient awareness. About three-fourths of patients were seeking information from healthcare experts rather than the Internet. It illustrated the need for ongoing doctor therapy and expanded appointment healthcare experts' time for patient education.

This research could be constrained by the cross-sectional layout of the sample. As this study was conducted at a single center, the results may not be representing a large population. And therefore, a multicentric study to get to the impact of various demographic patterns and sociocultural differences on KAP in patients with hypothyroidism could reveal more insights on thyroid disorder.

\section{CONCLUSION}

Our study highlighted the significance of investing appropriate time to provide patients with a comprehensive education to bridge the gaps in patient care. The findings also indicated that it be better for the understanding of the patients if health-care providers could provide patients with data sheets explaining the disease or having some pictorial/pamphlets about the disease's reality and myths.

\section{ACKNOWLEDGMENT}

We thank the Management and Faculties of all the departments and other staff for suggestions and support for completing this work.

\section{AUTHORS' CONTRIBUTIONS}

VDPG and SSM contributed to data collection and manuscript writing, SSR contributed to designing the study, follow-up, and final review.

\section{CONFLICTS OF INTEREST}

There are no conflicts of interest.

\section{AUTHORS' FUNDING}

No special grant has been obtained from any state, private, or supporting organization for this study.

\section{REFERENCES}

1. Unnikrishnan AG, Kalra S, Sahay RK, Bantwal G, John M, Tewari N. Prevalence of hypothyroidism in adults: An epidemiological study in eight cities of India. Indian J Endocrinol Metab 2013;17:647-52.

2. Swathi N, Kumar VV, Farjana M, Vardhan MV, Munendra M, Kumar GV. A prospective observational study on prevalence of hypothyroidism in a tertiary care teaching hospital. Int J Pharm Pharm Sci 2018;10:23-5.

3. Deepthi G, Sajeeth C. Prevalence of thyroid disorders in patients in two tertiary care hospitals at Palakkad: A prospective study. Int J Pharm Biol 2013;8:33-7.

4. Cooper DS. Clinical practice. Subclinical hypothyroidism. N Engl J Med 2001;345:260-5.

5. Roberts CG, Ladenson PW. Hypothyroidism. Lancet 2004;363:793-803.

6. Krassas GE, Poppe K, Glinoer D. Thyroid function and human reproductive health. Endocr Rev 2010;31:702-55.

7. Sood A, Pandav CS, Anand K, Sankar R, Karmarkar MG. Relevance and importance of universal salt iodization in India. Natl Med J India 1997;6:290-3.

8. Hebbar S, Kumar S, Amin S, Doizode S. Subclinical hypothyroidism in pregnancy; is there a need for pharmacological intervention? Int $\mathrm{J}$ Pharm Pharm Sci 2017;9:186-91.

9. Kataria J, Gill GK, Kaur M. Interrelationship of thyroid hormones, obesity, and prolactin in infertile women. Asian J Pharm Clin Res 2018;11:136-7.

10. Menon VU, Sundaram KR, Unnikrishnan AG, Jayakumar RV, Nair V, Kumar H. High prevalence of undetected thyroid disorders in an 
iodine sufficient adult South Indian population. J Indian Med Assoc 2009;107:72-7.

11. Nimmy NJ, Aneesh PM, Narmatha MP, Udupi RH, Binu KM. A survey on the prevalence of thyroid disorder induced by demography and food habits in South Indian population. Indian J Pharm Pract 2012;5:49-52.

12. Rai S, Sirohi S, Khatri AK, Dixit S, Saroshe S. Assesment of knowledge and awareness regarding the thyroid disorders among women of a cosmopolitan city of Central India. Natl J Community Med 2016; 7:219-22.

13. Kumar P, Khandelwal D, Mittal S, Dutta D, Kalra S, Katiyar P, et al.
Knowledge, awareness, practices and adherence to treatment of patients with primary hypothyroidism in Delhi. Indian J Endocrinol Metab 2017:21:429-33.

14. Sethi B, Khandwal D, Vyas U. A cross sectional survey to assess knowledge, attitude, and practices in patients with hypothyroidism in India. Thyroid Res Pract 2018;15:15-22.

15. Singh A, Sachan B, Malik NP, Sharma VK, Verma N, Singh CP. Knowledge awarness and practices (KAP) among patients with thyroid swelling attending cytology clinic in a medical college, Meerut. Indian J Clin Pract 2014;24:753-5. 